\title{
Reconhecimento da localidade de Rödersberg citada por Reinhold F. Hensel em 1867, para o Rio Grande do Sul, Brasil
}

\author{
Paulo A.C. Pereira ${ }^{1}$ \\ José W. Thomé ${ }^{2}$
}

\begin{abstract}
Recognition of locality of Rödersberg cited by Reinhold F. Hensel in 1867, from Rio Grande do Sul, Brasil. Old descriptions of species frequently present imprecise or even non-existing toponyms. Based on comparisons of old collecting maps by HENSEL (1867), it is suggested the river basin to which belongs the material collected and designed as a new species (Rio Caí basin), namely Chilina parva Martens, 1868 . The type-locality of this material, Rödersberg, can hardly be categorically affirmed, but as coordinates were raised, along other evidences, it is suggested that the actual toponym be Morro Reuter county, Rio Grande do Sul.

KEY WORDS. Chilina parva, Morro Reuter county, Reinhold Hensel, Rio Caí basin, Toponym, Rödersberg
\end{abstract}

Uma das grandes dificuldades do taxonomista, que se depara com revisões e descrições muito antigas, é a falta de indicação precisa das localidades de coleta. Estas informações são muitas vezes fundamentais para a correta determinação de espécies, estudos revisivos ou para inferências de novos táxons. Com freqüência também encontramos topônimos não expressos em vernáculo, dificultando assim a correta localização da procedência do material científico (PAPAVERO 1994). Como conseqüência, pode-se produzir uma série de ambigüidades taxonômicas.

O caso da localidade-tipo de Chilina parva Martens, 1868 (Mollusca, Gastropoda) pode ser tomado como exemplo.

O naturalista e geógrafo alemão Reinhold Friedrich Hensel, esteve no Brasil no período de 1863 a 1866. Sua incumbência, entre outras, era o colecionamento de informações, dados e material referentes à história natural do continente Sulamericano (MALABARBA 1989). Hensel foi enviado às colônias alemãs instaladas na Província de São Pedro do Rio Grande do Sul (atual estado do Rio Grande do $\mathrm{Sul}$ ) onde coletou entre outros organismos, moluscos.

MALABARBA (1989), em revisão do histórico de coletores e de espécies de peixes coletados no sistema da laguna dos Patos, afirmou que Hensel havia coletado somente neste sistema, no estado do Rio Grande do Sul, representado pelas bacias do rio dos Sinos, rio Jacuí, rio Guaíba e rio Caí, entre outros.

1) Departamento de Biologia Animal e Vegetal, Universidade Estadual de Londrina. 86051-970 Londrina, Paraná, Brasil. Bolsista do CNPq.

E-mail: cypriano@npd.uel.br.

2) Laboratório de Malacologia, Pontifícia Universidade Católica do Rio Grande do Sul. 90619-900 Porto Alegre, Rio Grande do Sul, Brasil. Com auxilios ebolsas do CNPq, CAPES e FAPERGS.

E-mail: thomejw@pucrs.br 
Uma das localidades de coleta de Hensel foi Rödersberg. O autor afirmou que o topônimo também era grafado como Reitersberg. Ainda descreve que essa localidade seria na encosta da Serra (encosta do planalto Sul Rio Grandense), próximo à colônia de São Leopoldo, cerca de $30 \mathrm{~km}$ à nordeste de Porto Alegre (HENSEL 1867). Um molusco coletado por ele nessa localidade, foi descrito mais tarde por MARTENS (1868), como uma nova espécie: Chilina parva.

Ao longo do tempo o topônimo Rödersberg ou Reitersberg entrou em desuso, pois o topônimo não é mais encontrado em mapas e índices de localidades do Rio Grande do Sul.

De posse do mapa publicado por HENSEL (1867), que demonstra o itinerário de sua expedição científica, verificou-se que a localidade-tipo de Chilina parva, encontra-se citada entre Colonien von São Leopoldo e Colonien von Neu Petropolis (Fig. 1). Estas localidades podem ser identificadas em mapas atuais como os municípios de São Leopoldo e Nova Petrópolis, respectivamente.

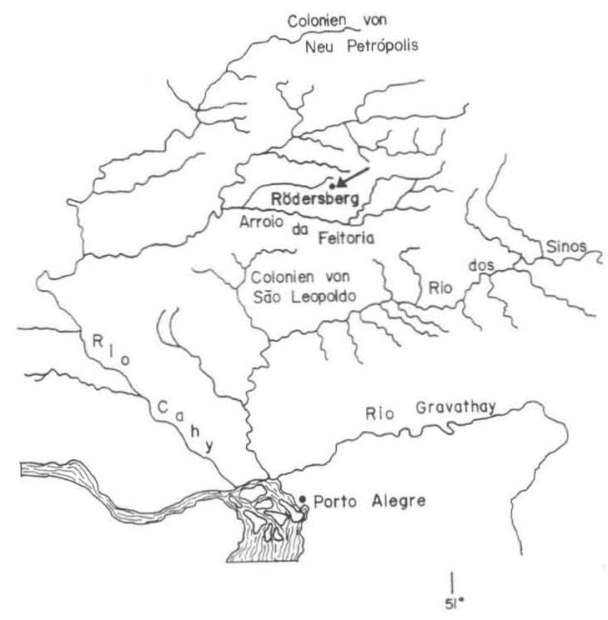

Fig. 1. Reprodução parcial, modificada do mapa de HENSEL (1867), com indicação da localidade-tipo de Rödersberg.

Ainda, pelo mapa de Hensel, a localidade de Rödersberg possuiria as coordenadas aproximadas de $29^{\circ} 35^{\prime} \mathrm{S}$ e $51^{\circ} 05^{\prime} \mathrm{W}$.

Concordamos quanto a localidade de Rödersberg pertencer ao sistema da laguna dos Patos. Mais ainda, a localidade-tipo está vinculada à bacia do rio Caí. Aventa-se que o nome atual para a localidade-tipo pode ser o atual município de Morro Reuter, devido à proximidade de coordenadas e a latinização das palavras röders ou reiters por colonizadores alemães e a tradução de berg que é morro.

Segundo IBGE (1982), Morro Reuter possui as coordenadas aproximadas de $29^{\circ} 35^{\prime}$ 'S e $51^{\circ} 05^{\prime} \mathrm{W}$, idêntica à indicada por HENSEL (1867).

Tal reconhecimento fundamentou a localização para coleta e análise de topótipos de Chilina parva, propiciando revisões taxonômicas que serão sugeridas em trabalhos subseqüentes. 
AGRADECIMENTOS. Ao Dr. Oscar Akio Shibatta (UEL) e a Dra. Angela T. Silva e Souza (UEL) pela leitura crítica e sugestões; ao Conselho Nacional de Pesquisa (CNPq) pelo suporte financeiro dotado aos autores; à Coordenadoria de Aperfeiçoamento de Pessoal de Nível Superior (CAPES) e Fundação de Amparo a Pesquisa do Rio Grande do Sul (FAPERGS) pelo suporte financeiro ao segundo autor.

\section{REFERÊNCIAS BIBLIOGRÁFICAS}

HENSEL, R. 1867. Beiträge zur näheren Kenntniss der brasilianischen Provinz São Pedro do Rio Grande do Sul. Zeitschrift der Gesellschaft für Erdkunde zu Berlin 2: 227-269, 342-376.

IBGE. 1982. Carta Intenacional do Mundo ao Milionésimo. Folha Porto Alegre, SH-22, $3^{\mathrm{a}}$ ed., escala $-1: 1.000 .000$

MalabarBA, L.R. 1989. Histórico sistemático e lista comentada das espécies de peixes de água doce do sistema da laguna dos Patos, Rio Grande do Sul, Brasil. Comun. Mus. Ciênc. PUCRS, Sér. zool., 2 (8): 107-179.

MARTENS, E. VON. 1868. Über südbrasilianische Land-und Süsswassermollusken. Nach den Sammlungen von Dr. R. Hensel. Malak. Blätter 15 (2): 169-217. PaPAVERO, N. 1994. Fundamentos práticos de taxonomia zoológica. São Paulo, Unesp, $2^{\mathrm{a}}$ ed., 285p.

Recebido em 02.IV.1998; aceito em 20.VIII.1999. 